\title{
Semantic Shifting: From the Oppression to Minority Culture to the Embodiment of Politician's Anxiety
}

\author{
Peiqiao Liu ${ }^{1, *}$ \\ ${ }^{1}$ Affiliated Middle School to Inner Mongolia Normal University, Hohhot, Inner Mongolia Autonomous Region, \\ China,01000. \\ *Corresponding author: lpqlpq7575@163.com
}

\begin{abstract}
In modern times, semantic shifting is mostly used as an instrumental theory in language researches, computer and other fields, as an academic topic mostly mentioned in academic researches, be classified as a research method of postmodern social phenomena such as racial discrimination, gender discrimination and sexual orientation discrimination, but ignore its own semiotic and structural connotation. This is a point for discussion. The pure linguistic and symbolic meaning associated with itself cannot be ignored and can be studied, and people can fully explore its important social significance and its linguistic essence through its rational analysis. Therefore, this article mainly draws lessons from Foucault Lacan's theory and its researchers' scientific research methods and results, from the necessary demonstration of using post structuralism to explore the connotation method of semantic shifting, and it is proved that semantic shifting actually comes from the anxiety of politicians in the early stage of democratic politics.
\end{abstract}

Keywords: Post structuralism, Lacan, Foucault, Semantic shifting, Linguistic

\section{INTRODUCTION}

This article will quote Foucault's theory of poststructuralist social relations and master-slave dialectics, Lacan's psychoanalysis and linguistic theory are mentioned and compared with the phenomenon of semantic shifting of specific derogatory words: it does not have the fuzziness and uncertainty in the general cognition of linguists. Its historical gradual change actually has a consistent essence, that is, a screening of minority culture, where the culture is "deleted",and the article will also try to demonstrate the reason why the article uses these theories, the article thinks for semantic shifting, if we want to investigate its essence, we can not use the idea of structuralism to understand it. This article tends to understand the phenomenon of semantic shifting as the sliding of symbolic meaning corresponding to words, which is the embodiment of the Foucault spatial feature of "social power can be realized through the possession of social knowledge". From this, we will find that behind the semantic change with history, it is called the performance of the right movement caused by the gradual change of symbolic culture, and take this as the center to explore the essence of Lacanic anxiety behind the semantic change, the article wants to achieve three goals, firstly, demonstrate why we can't use structuralism to understand the phenomenon of semantic shifting; secondly, reflect its oppression of minority culture by the power class with social knowledge in Lacan linguistics by using this method of deriving conclusions from the phenomenon of language use in real life; thirdly, find the essence of bourgeois anxiety about the concept of nonoccurrence and the Other.

\section{ANALYSIS}

\subsection{Semantic shifting is not suitable to be explained by structuralist}

This part will start from the semantic shifting of the word "innovation". At present, innovation is mostly regarded as the core driving force of a country's development. For more than 2500 years, as a concept, "innovation" has always been regarded as a derogatory word[1]. It is considered to subvert the existing order, destroy the social structure and deny religious authority. In 1548, King Edward VI proclaimed $<<$ A Proclamation Against Those that Doeth Innovate $>>$, which banned artificial innovation at the national level, which is a prominent embodiment.

It is not difficult to see that, for the purpose of maintaining the feudal rule of fundamentalism and the 
authority of religion, people who master social power are maintaining social culture and preventing its changes. Foucault adheres to the social relations and power structure of the objective world and is shaped by discourse and knowledge in the spiritual field. Foucault believes that as long as he masters the production of knowledge, any individual or social group can obtain "certain" social power. The article thinks Foucault's discussion on this thought is structuralist, Moreover, it pays more attention to social relations, and the power structure has more impact on the changes in people's spiritual field. The discourse and knowledge in the spiritual field have more impact on social relations and power structure. Foucault's theory has been influenced by Althusser. Some people think that for Foucault, the distribution of power in his theory is more decentralized as long as he masters the production of knowledge[2]. Any individual and the social group can obtain certain social power. Compared with Althusser's theory involving only the bourgeoisie and the proletariat, Foucault's theory is more flexible[2]. However, it can be seen from his words that he did not get rid of the ideological theory of centralized distribution of class rights. In fact, his thought is still structuralist. Take the example of Edward VI just cited. From the perspective of post structuralism, the article thinks if we analyze this phenomenon according to Foucault's theory, there will only be such a result: restricting innovation is the result of the interaction between the feudal power of Royal religion and the power of social intellectual property rights, and the class power occupying a more important position will make the system very stable, so it will ignore the key points and lead to mistakes. The production of knowledge will affect people's judgment. Here we might as well talk about the dialectics of Master Slave: selfconsciousness is a dual unity. Hegel explains it this way in Spiritual Phenomenology[3]: the slave loses himself, so he sublates freedom, because he also sees that the master does not really exist, but sees himself in the master out of fear and self-consciousness, the innovators mentioned in this article are bound to sublate their dependence. This pure negative force will be transformed into real independence. The promulgation of the bill has produced the knowledge that "anti innovation is legitimate" and turned innovators into their slaves. However, we can see that the Enlightenment has taken place, and this negative force is greater than the so-called Royal religious rights, the emergence of this phenomenon has to take into account many factors such as history, humanities and geography. Therefore, the article thinks post structuralism is a banner that can be played by people who are very careful and have enough knowledge. From the fear of change in the twentieth century to the fear of stagnation, even today, many innovations have been widely accepted by the public after several years of precipitation. Continue to discuss the semantic shifting of innovation. In the middle ages, another phenomenon deserves attention. Due to the need to understand the
Bible, innovation was once added with the meaning of return and recovery. The problem is that a word with quite a personal color was given, and a large number was used in the meaning of the word in the context of "collective", the theory of American scholar E.M. Rogers points out[4]: "The key factor of innovation is the compatibility between individual ideas and innovation under the social system. Therefore, the whole innovation process will be restricted by the existence of a specific order." Remove the sharp core of culture itself and give it a meaning completely contrary to the original meaning. While interpreting the Bible, it has doubled its power. This is a deeply hidden cultural output. It makes people unable to realize that their cultural power is in a weak position, and this cannot become the fuse of the power source of "fear" in the master slave dialectics, different from the above solution is to enact laws, the direct change of religion to the symbol interpretation system has caused greater trauma to innovation, which has led to the rupture of the symbol interpretation chain to some extent, and the negative power caused by fear of change has disappeared, this is also one of the reasons why the term innovation has continued its derogatory meaning for thousands of years. What should be noted is that, here's just one reason. There are many basic reasons for the shifting of innovation from derogatory to commendatory, but taking this as an example, the article think it is certain that we cannot understand the linguistic phenomenon of semantic shifting in a structuralist way.

\subsection{On the oppression of semantic shifting on minority culture}

Through the above argument, it can be understood that the study of this phenomenon must be discussed from multiple angles, and Lacan's linguistic interpretation has priority. The article thinks the explanation of this word still needs to be put in a specific context. Let's take the above innovation for example. As mentioned above, one of the reasons why innovation has changed from derogatory words to commendatory words is that the negative movement of spirit under oppression in the dialectics of masters and slaves weakens the subjectivity between masters and slaves, while Foucault's "history is divided into different stages and different manifestations in different stages" is the appearance of the increase of this negative movement in life. Due to the emergence of modern bourgeois revolution, industrial revolution and two world wars in a short time, comprehensive informatization has brought ideological impact to people and lost the opportunity to occasionally touch the original happiness of the real world, resulting in people falling into anxiety and starting to strengthen their efforts to find the object(a), and in the process of searching, they will have fun, or abstinence for the purpose of spiritual pleasure, their way of exploration, as Foucault said, entered the modern knowledge-based period and began self representation. This exploration gradually changed 
from the pursuit of similarity to a more rational imitation. However, people do not have the ability to push the phenomenon, which also determines that people will eventually ignore some things, non-symbolization of object(a). So their pursuit from the beginning is a mistake. They willingly substitute people or things outside the atomized family and even words into the image of the Other who always stare at them. In this way, we can further understand the connotation of the meaning change of innovative words: most European and American countries have national religions, the innovation in breaking through the fundamentalist religion reflects people's awe of the Other and their search for object(a), because they are also maintaining the renewal of the Other and maintaining his authority and reality, but they do not pay attention to the definition of $\operatorname{object}(\mathrm{a})$ : it is something that cannot be symbolized. This is reflected in their grabbing and naming of new things: some names that period of many regions in Asia, Africa and Latin America are the same as the names of locally produced crops or minerals, which implies that these explorers are actually exploring the original happiness implied by these goods. This theory can also be applied to a typical word "queer". From its inception to the 1990s, its meaning was "abnormal". In the 1990s, firstly, it combined the names of gays and lesbians, they use this word as a name for themselves to challenge the dichotomy of heterosexuality and homosexuality[5], and pursued the object(a) of a desire of being understood.The performance, variability, discontinuity and process of such a concept itself actually reflected their praise for the other. At that time, they founded an LGBTQ alliance and wanted to touch the corners of the real world through this rebellion against the mainstream culture. This negative movement reflects the oppressive nature of semantic shifting on minority culture from the perspective of Lacan linguistics

\subsection{On the essence of anxiety behind semantic shifting}

After the above deconstruction analysis of the two words from the perspective of Lacan linguistics, the article wants to focus on the further understanding of the word "queer", because she is a word created by politicians in the 1990s, and the article just want to reflect the essence of semantic shifting and bourgeois anxiety through the implied political ethics behind the word.From Lacan ethics, we can know that people's real desire is to maintain the creation of desire and cover up the traumatic pleasure with the beauty of imagination. Here, we have to talk about class and politics. For example, the two words just used as an example have their meaning changes controlled by the bourgeoisie to some extent, after combining Foucault's theory, the article want to put forward that in fact, semantic shifting is also an embodiment of people's knowledge-based and cognitive methods limited by the times. However, this article does not want to emphasize that its change originates from the change of the times, but wants to emphasize that this change itself is fixed. Why take the word "queer" as an example, because it is a phenomenon in the United States where the spatial relationship of capitalism has matured, it is the clearest embodiment of the interdependent logical relationship between cultural significance and the production of identity. In his research, Choon-Piew Pow concluded that spatial relations promoted the social identity and cultural identity of the new rich class in Chinese cities, making them clear the boundary between the self and the other[6]. This phenomenon can also be placed in the United States: in the book of American writer Gore Robin[4], it is mentioned that the conceptual invention right of queer theory belongs to feminist Teresade Lauretis, her view is that the replacement of lesbian and gay references by queer theory will lead to the violation of the original intention of emphasizing the respective particularity of gays and lesbians, and the problem of feminism may also be marginalized. From the perspective of Lacan ethics, it can be seen that the bourgeoisie takes advantage of the appearance of homosexuals' incomplete cognition of their own desires and one-sided sexual concept of freedom of statement, and completely does not mention the rebellion against social discrimination and traditional customs. The trauma brought by homosexuals' rebellion is what homosexuals get in the end, and their pleasure can be satisfied in other ways, the purpose of classifying American citizens in terms of race, religious belief and other aspects from the current American political arena are to maintain the production of knowledge through identity politics and continuously obtain social power. This is the reason why semantic shifting is class: through knowledge archaeology, we can find that in the East, In order to maintain the ruling landlord class, China's Qin Dynasty tried its best to integrate the cultural belt and maintain the political stability linked by geographical relations.In the west, after the establishment of a unified Republic, Rome issued special laws for different regions to establish national subjectivity to maintain regional stability. The modern western political style is quite different from it. Due to the universality of democracy and the openness of space, democratic countries have to implement regional relative power centralization in some way. The regional dispersion of power leads to regional differences in cultural output, and due to historical factors, Politicians began to publicize and use minority culture in the north of the United States. The argument has not ended here,the narrow sense of the word minority is the small number. Of course, today's LGBTQ group is very large, but why did early politicians choose this direction for use? This stems from the anxiety of these bourgeois politicians, and this anxiety is Lacanic[7]. Marx investigated language from the social essence of language -- "language is the object of people's relationship with each other.'[8] They worry about an unknown crisis, do not know what they look like in people's hearts, and thus understand their anxiety. Due to the cultural atmosphere and class identity 
created by capitalist space, minorities have inherent disadvantages in their reasonable self-awareness, politicians control the anxiety of minorities through speeches and relevant policies to form a regional campaign group. Therefore, the class, historical, spatial and political connotation behind the language phenomenon of semantic shifting can be identified through Lacan's and Foucault's theories.

\section{CONCLUSION}

After a certain understanding of linguistics, the article found that the phenomenon of semantic shifting can be integrated with ethics, sociology and even economics. This transformation has unique historicity. Therefore, through the dialectical analysis of Foucault's theory, this article first obtains the necessity of using post structuralism to explore the connotation of semantic shifting, and through this method, Combined with Lacan linguistics, it is found that semantic shifting itself has a historical stage and class. This paper runs through the full text with Foucault's method of knowledge archaeology, and at the end of the article, combined with Lacan ethics, comes to the conclusion that the origin of semantic shifting is related to the Lacan anxiety of politicians in the early stage of democratic politics. The article finds that the specific words created by many disciplines can communicate with the knowledge of other disciplines, so as to form a structured and diversified interpretation and application system, this is also the author's view that the integration of disciplines can bring academic progress. For words and things, I don't think they are just a tool phenomenon to be used, and even many of them need to be explained. Let the academic language of one discipline communicate with other disciplines, and reinterpret it in the current context. Transformation and structured understanding of terms in different disciplines is a direction worthy of opening up and attention

\section{ACKNOWLEDGMENT}

After completing this article, I would like to thank Professor Justin Khoo, who helps me connect linguistics with real life and has his own unique educational style, as well as Teacher Delin Deng, who helps me understand and review, deepen the connotation of knowledge and deepen my impression. I am grateful for their help.

\section{REFERENCES}

[1]Han Jinqi. The shifting of "innovation" from derogatory to commendatory discourse -- a study from a philosophical perspective $[\mathrm{J}]$. Wuling journal,2019,44(01):24-29.

[2]Qian Junxi. Social theory in the context of post structuralism: Michel Foucault and Henry Lefebvre [J]. Human geography,2013,28(02):45-52.
[3]Hegel. Phenomenology of spirit (Volume The article) [M]. Translated by He Lin, Wang Jiuxing. Beijing: Commercial Press, 1979.

[4]E.M. Rogers. diffusion of innovation [M]. Translated by Tang Xingtong, Zheng Changqing, et al. Beijing: Electronic Industry Press, 2016

[5]Gayle Rubin. Queer theory. Western sexual thoughts in the 1990s [M]. Translated by Li Yinhe. Current affairs press, 2000

[6]Pow C P. Gated communities in China: class, privilege and the moral politics of good life[M]. London and New York: Routledge, 2009.

[7] Lacan, Le Séminaire X: L'angoisse, 1962-1963, Éditions du Seuil, Paris 2004

[8]Zhou Wenlian. "A linguistic study of Lacan's unconscious theory -- between Freud, Saussure and Marx." Nanjing Social Sciences .06(2020):2328+39.doi:10.15937/j.cnki.issn10018263.2020.06.004. 